\title{
Anti-Microbial Activity of Hempseed Oil and Sage Oil against Streptococcus mutans and Candida albicans: An In-Vitro Study
}

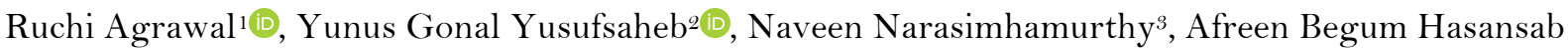 \\ Itagi ${ }^{+}\left(\mathbb{0}\right.$, Reena Kulshrestha ${ }^{5}$, Santosh Rayagouda Patil ${ }^{6}[0$
}

\footnotetext{
'Department of Public Health Dentistry, New Horizon Dental College and Research Institute, Bilaspur, India. ${ }^{2}$ ESIC Dental College, Kalaburgi, India.

${ }^{3}$ Department of Public Health Dentistry, Rungta College of Dental Sciences and Research, Bhilai, India.

${ }^{4}$ Department of Physiology, All India Institute of Medical Sciences, Mangalagiri, Andhra Pradesh, India.

${ }^{5}$ Department of Physiology, Rungta College of Dental Sciences and Research, Bhilai, India.

${ }^{6}$ Department of Oral Medicine and Radiology, New Horizon Dental College and Research Institute, Bilaspur, India.
}

Correspondence: Santosh R. Patil, Department of Oral Medicine and Radiology, New Horizon Dental College and Research Institute, Sakri, Bilaspur, Chhattisgarh 495001, India. E-mail: drpsantosh@gmail.com

Academic Editor: Yuri Wanderley Cavalcanti

Received: 04 December 2020 / Review: 17 February 2021 / Accepted: 05 March 2021

How to cite: Agrawal R, Yusufsaheb YG, Narasimhamurthy N, Itagi ABH, Kulshrestha R, Patil SR. Anti-microbial activity of hempseed oil and sage oil against Streptococcus mutans and Candida albicans: an in-vitro study. Pesqui Bras Odontopediatria Clín Integr. 2021; 21:e0251. https://doi.org/10.1590/pboci.2021.115

\begin{abstract}
Objective: To assess the anti-microbial activity of sage oil and hempseed oil against Streptococcus mutans and Candida albicans. Material and Methods: The sage oil and hempseed oil in pure extract form were collected from an authorized government organization. The anti-microbial activity from the oils was assessed by Kirby-Bauer disc diffusion method. Standard antibiotics Vancomycin and Fluconazole were taken as a positive control for Streptococcus mutans and Candida albicans, respectively. The mean zone of inhibition (ZOI) was measured at 24 hours, 48 hours and 72 hours by HI-MEDIAs antibiotic zone scale. One-way Analysis of variance with Tukey's Post Hoc was applied for statistical analysis. Results: The mean zone of inhibition of sage oil and hempseed oil at 24 hours, 48 hours and 72 hours against Streptococcus mutans was $(7.0 \pm 4.24,9.1 \pm 3.71$ and $8.4 \pm 3.02)$ and $(0.0,3.2 \pm 0.75,1.9 \pm 1.24)$ respectively. The zone of inhibition against Candida albicans 24 hours, 48 hours and 72 hours for sage oil $(2.80 \pm 1.151,6.70 \pm 1.30$ and $6.30 \pm 1.44)$, hempseed oil $(0.0,3.80 \pm 0.75,3.10 \pm 0.41)$. Sage oil presented potential anti-microbial activity against Streptococcus mutans and Candida albicans. Comparing the anti-microbial efficacy, standard antibiotic (Vancomycin/Fluconazole) was more effective than test oils. Conclusion: Test oils showed antibacterial and anti-fungal activity against Streptococcus mutans and Candida albicans. Among these, sage oil showed efficacy at 24 hours, while hempseed oil did not show any effect at this time point. Further studies are needed to affirm the same and test their efficacy in different forms and concentrations.
\end{abstract}

Keywords: Anti-Bacterial Agents; Salvia officinalis; Cannabis; Plants, Medicinal. 


\section{Introduction}

Dental caries is one of the most prevalent dental diseases [1]. Streptococcus mutans, a Gram-positive bacteria, play a vital role in progression of caries by producing glucans and acids, which allow them to suppress the activity of the non-cariogenic commensal at low ph in oral cavity [2]. Candida albicans commonly colonizes human mucosal surfaces and are prevalent in oral mucosa. Co-adhesion between fungi and bacteria in oral cavity is pivotal for fungal colonization [3].

Various drugs have been tested and are proved to be effective against Streptococcus mutans and Candida albicans. However, because of increasing resistance to these synthetic drugs, it is necessary to test for newer drugs. Due to the current belief that 'green medicine' is safe and more dependable than expensive synthetic drugs, natural products are being subjected to test their anti-microbial potency [4].

Hemp plant (Cannabis sativa) belongs to Family Cannabinaceae, popularly known for its preparation like Marijuana, Bhang, Ganja, Charas, etc. [5]. It has been found to be anti-bacterial, anti-ulcerative, antiinflammatory, and anti-arthritic [6], anti-phlegmatic and also used as an anesthetic agent [7]. The most psychologically active component in Cannabis plant is delta-9-tetrahydrocannabinol (THC), which is used to treat side effects in patients undergoing chemotherapy [7,8].

Sage plant (Salvia officinalis L.), a Lamiaceae family member, is anti-bacterial, anti-fungal, anti-oxidant, anti-spasmodic and anti-diuretic in action [9]. It is also used as a local anesthetic for skin, in aromatherapy and in the treatment of dermatitis [10]. It is also found to be effective in chronic illnesses such as obesity, diabetes, depression, dementia, lupus, autism, heart disease, and cancer [11]. Even though limited studies were conducted to test the anti-microbial efficacy of these oils against oral pathogens, but the results were promising. Beheshti-Rouy et al. [12] recommended that sage mouth rinse could be used as an adjunct for conventional methods of plaque control against dental caries. Stahl and Vasudevan [13] concluded that Cannabinoids have the potential to be used as an effective anti-bacterial agent against dental plaque-associated bacteria. With this background, the present study was designed and undertaken to assess the anti-microbial activity of sage oil and hempseed oil against Streptococcus mutans and Candida albicans.

\section{Material and Methods}

\section{Study Design and Ethical Clearance}

This in-vitro study was conducted in the Department of Microbiology, Rungta College of Dental Sciences and Research, Bhilai, India. The ethical clearance was obtained from the institutional review board of the institute (Protocol No. 18/023).

\section{Materials}

Sage plant (Salvia officinalis L.) and Hemp plant (Cannabis sativa) were used as sources of antimicrobial agents. Streptococcus mutans (MTCC 497) and Candida albicans (MTCC 3958) were used as test microorganisms.

\section{Essential Oils Acquisition}

Sage oil and hemp oil were collected from Chhattisgarh State Minor Forest Produce Federation (Sanjeevani Retail Outlet, Durg, India). The package showed that sage oil and hempseed oil were extracted from the steam distillation and cold expression methods. 
Preparation of Antibiotic and Test Oils Sensitivity Testing Disc

The Kirby-Bauer disc diffusion technique [14] was used to determine the anti-microbial activity of the two oils. Sterile Whatman No. 1 paper was punched into $5 \mathrm{~mm}$ diameter disc size. The discs were placed in a glass Petri plate and oven; sterilized at $170^{\circ} \mathrm{C}$ for 1 hour. Five separate sterile discs were soaked in the test oil, antibiotic, and distilled water (negative control) for 24 hours for proper absorption, after which it was allowed to dry for 24 hours.

Preparation of Culture Agar Plates

Mitis Salivarius agar and Sabouraud Dextrose agar was used as selective media for culture of Streptococcus mutans and Candida albicans, respectively. Agar was poured into sterile Petri dishes (Borosil Glass Works Ltd., Mumbai, India) of size $90 \mathrm{~mm}$, in a sterile lamellar airflow chamber which was equipped with ultraviolet light and high-efficiency particulate air filter, sterile Petri-dishes were placed and about $20 \mathrm{ml}$ of molten agar were poured in these Petri-dishes. Appropriate precautions were taken to avoid contamination to culture plates. The growth of freshly sub-cultured isolates was matched with a turbidity of 0.5 on McFarland scale $[15]$.

\section{Disc Diffusion Method}

Each test plate comprised of 4 discs viz., one positive control (Vancomycin disc/Fluconazole disc), one negative control and two discs treated with tests oils. Five such plates were prepared and incubated for 24 hours, 48 hours, and 72 hours. A similar procedure was carried out for both test microorganisms separately. After incubation, the plates were examined for the zone of inhibition (ZOI) using HI-MEDIAs antibiotic zone scale.

\section{Statistical Analysis}

The data obtained were analyzed using SPSS (Statistical Package for Social Sciences), version 21.0 (IBM SPSS, Chicago, IL, USA). Descriptive statistics in terms of mean and standard deviation were calculated. For Multiple group comparison of the mean zones of inhibition between the test oils and standard antibiotic one-way Analysis of variance was used and for group-wise comparison, Tukey's post hoc was performed. A pvalue $\leq 0.05$ was considered statistically significant.

\section{Results}

The zone of inhibition around the discs against anti-microbial was calculated using HI-antibiotic zone scale. The mean zone of inhibition of sage oil and hempseed oil at 24 hours, 48 hours and 72 hours against Streptococcus mutans was $(7.0 \pm 4.24,9.1 \pm 3.71$ and $8.4 \pm 3.02)$ and $(0.0,3.2 \pm 0.75,1.9 \pm 1.24)$, respectively. The mean zone of inhibition of both the test oils was less than standard antibiotic Vancomycin at 24 hours, 48 hours, and 72 hours which was $20.0 \pm 4.8,27.9 \pm 1.34$ and 24.4 \pm 0.96 , respectively (Figure 1).

The zone of inhibition against Candida albicans 24 hours, 48 hours, and 72 hours for sage oil (2.80 \pm $1.151,6.70 \pm 1.30$ and $6.30 \pm 1.44)$, hempseed oil (0.0, $3.80 \pm 0.75,3.10 \pm 0.41)$ and standard anti-fungal agent fluconazole $(25.60 \pm 1.14,26.30 \pm 1.25,24.80 \pm 1.64)$, respectively. The ZOI measured for anti-fungal agent fluconazole was markedly high compared to both the test oils, i.e., sage oil and hempseed oil (Figure 2). 


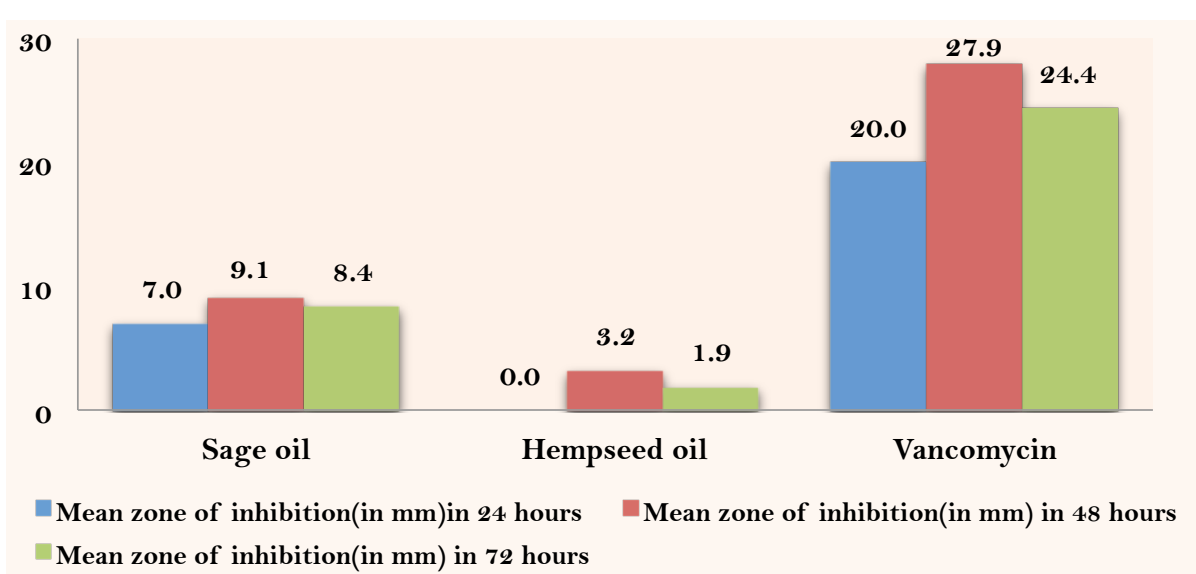

Figure 1. Anti-microbial activity of the sage oil, hempseed oil and vancomycin against Streptococcus mutans at 24 hours, 48 hours and 72 hours.

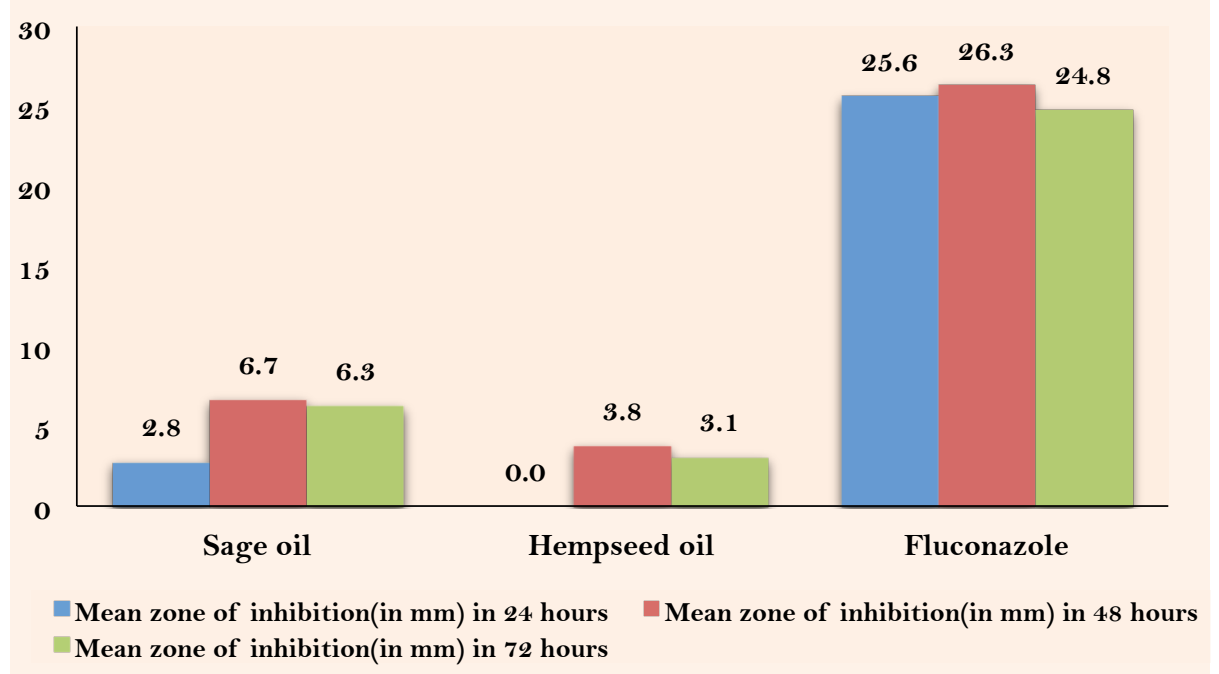

Figure 2. Anti-microbial activity of the sage oil, hempseed oil and fluconazole against Candida albicans at 24 hours, 48 hours and 72 hours.

Hempseed oil and sage oil were active against both the microorganisms, i.e., Streptococcus mutans and Candida albicans. Sage oil was more effective against Streptococcus mutans and Candida albicans than Hemp oil and standard antibiotics, i.e., Vancomycin (Streptococcus mutans) and Fluconazole (Candida albicans) were more effective against both the test organism compared to test oils. Analysis of variance with post-hoc showed a statistically significant difference in anti-microbial activity between sage oil, hempseed oil and vancomycin for Streptococcus mutans at 24, 48, and 72 hours $(\mathrm{p}<0.00)$. Post-hoc also showed a statistically significant difference between the test oils at 24 hours, 48 hours, and 72 hours $(p=0.01, p=0.004$, and $p=0.005)$, respectively (Table 1).

Similarly, against Candida albicans, analysis of variance test showed a statistically significant difference between standard anti-fungal agent fluconazole and the test oils $(\mathrm{p}<0.00)$. Post-hoc also showed a statistically significant difference between both the test oils at 24 hours, 48 hours and 72 hours $(\mathrm{p}=0.042, \mathrm{p}=0.004$, and $\mathrm{p}=0.001)$, respectively (Table 2$)$. 
Table 1. Intergroup comparisons of the sage oil, hempseed oil and vancomycin against Streptococcus mutans at 24 hours, 48 hours and 72 hours.

\begin{tabular}{|c|c|c|c|c|}
\hline Dependent Variables & Comparison & $\begin{array}{c}\text { 24 Hours } \\
\text { p-value }\end{array}$ & $\begin{array}{c}48 \text { Hours } \\
\text { p-value }\end{array}$ & $\begin{array}{c}72 \text { Hours } \\
\text { p-value }\end{array}$ \\
\hline \multirow[t]{2}{*}{ Sage Oil } & Hempseed Oil & 0.001 & 0.004 & 0.005 \\
\hline & Antibiotic & 0.000 & 0.000 & 0.000 \\
\hline \multirow[t]{2}{*}{ Hempseed Oil } & Sage Oil & 0.001 & 0.004 & 0.005 \\
\hline & Antibiotic & 0.000 & 0.000 & 0.000 \\
\hline \multirow[t]{2}{*}{ Fluconazole } & Sage Oil & 0.000 & 0.000 & 0.000 \\
\hline & Hempseed Oil & 0.000 & 0.000 & 0.000 \\
\hline
\end{tabular}

Post-hoc Tukey HSD.

Table 2. Intergroup comparisons of the sage oil, hempseed oil and vancomycin against Candida albicans at 24 hours, 48 hours and 72 hours.

\begin{tabular}{llccc}
\hline \multicolumn{1}{c}{ Dependent Variables } & Comparison & $\begin{array}{c}\text { 24 Hours } \\
\text { p-value }\end{array}$ & $\begin{array}{c}\text { 48 Hours } \\
\text { p-value }\end{array}$ & $\begin{array}{c}\mathbf{7 2} \text { Hours } \\
\text { p-value }\end{array}$ \\
\hline Sage Oil & Hempseed oil & 0.042 & 0.004 & 0.001 \\
& Antibiotic & 0.000 & 0.000 & 0.000 \\
Hempseed Oil & Sage oil & 0.042 & 0.004 & 0.001 \\
& Antibiotic & 0.000 & 0.000 & 0.000 \\
Fluconazole & Sage oil & 0.000 & 0.000 & 0.000 \\
& Hempseed oil & 0.000 & 0.000 & 0.000 \\
\hline
\end{tabular}

Post-hoc Tukey HSD.

\section{Discussion}

Streptococcus mutans is a prime etiologic agent for dental caries and having high prevalence in dental biofilms, where Candida albicans also resides, and interaction between the two mediate cariogenic developments. Main purpose of this study was to test the medicinal plants which can be used to inhibit the growth of oral pathogens namely Streptococcus mutans and Candida albicans.

The genus Salvia L. is mainly cultivated in Mediterranean, Southeast Africa, and Central and South America. It is cultivated for culinary, medicinal, and ornamental purposes. Its anti-microbial activity against several microorganisms has been reported for decades. Some major compounds are present in oil like 1,8cineole, $\beta$-thujone, camphor, borneol and p-cymene [16]. In the present study, mean ZOI (in mm) by sage oil against Streptococcus mutans was found to be $7.0 \pm 4.24 \mathrm{~mm}$ at 24 hours which is in corroboration with the study conducted by Pierozan et al. [17], (8.7 mm at 24 hours). Anti-microbial activity of sage oil at 24 hours against Candida albicans was found to be $2.80 \pm 1.151 \mathrm{~mm}$, which is in contrast with the study conducted by Sookto et al. [18], who observed ZOI of $31.5 \mathrm{~mm}$ at 24 hours. This difference may be because of the concentration of oil used in this study and the process of extraction of oil from the plants. One more reason may be the strains of Candida albicans in both the study may be different. The sage oil anti-microbial activity was maximum at 48 hours and then declined at 72 hours.

In the present study, hempseed oil showed no anti-microbial activity at 24 hours against both the test organism. At 48 hours, hempseed oil showed ZOI of $3.2 \pm 0.75 \mathrm{~mm}$ against Streptococcus mutans. A similar finding is seen in a study conducted by Verma et al. [7], which shows $8.4 \mathrm{~mm}$ of ZOI against Streptococcus mutans. Against Candida albicans, hemp oil showed slight anti-microbial activity (ZOI=3.80 \pm $0.75 \mathrm{~mm}$ ) at 48 hours, which contrasts with the study conducted by Ali et al. [5]. The authors noted a mean ZOI of $13 \mathrm{~mm}$ on Methanol extract of whole plant and the reason for this difference may be the use of whole plant extract in their study [5], while in the present study, oil was extracted by seeds of whole plant by cold expression method. 
The main limitation of the present study is that test oils were not tested at different concentrations. Secondly, the purity of the test oil could not be assessed as it was obtained in oil form.

\section{Conclusion}

Test oils showed anti-bacterial and anti-fungal activity against Streptococcus mutans and Candida albicans, respectively. Among these, sage oil showed efficacy at 24 hours, while hempseed oil did not show any effect at this time point. Further studies are needed to affirm the same and test their efficacy in different forms and concentrations. These oils can be used to prevent oral diseases and can act as a natural adjunct to synthetic antibiotics. These oils can also be used as chemical plaque control agents and is a cost-effective and efficient means of plaque control.

\section{Authors' Contributions}

\begin{tabular}{|c|c|c|}
\hline RA & (iD) https://orcid.org/0000-0001-8024-3317 & Conceptualization, Investigation and Data Curation. \\
\hline YGY & (iD) https://orcid.org/0000-0001-6453-1861 & Conceptualization, Validation, Formal Analysis and Project Administration. \\
\hline $\mathrm{NN}$ & -- & Visualization and Supervision. \\
\hline ABHI & https://orcid.org/0000-0003-2650-6993 & Formal Analysis and Writing - Original Draft. \\
\hline RK & (iD) https://orcid.org/0000-0001-6493-170X & Methodology and Investigation. \\
\hline SRP & (iD) https://orcid.org/0000-0003-0715-497X & Conceptualization, Data Curation and Writing - Review and Editing. \\
\hline
\end{tabular}

\section{Financial Support}

None.

\section{Conflict of Interest}

The authors declare no conflicts of interest.

\section{Data Availability}

The data used to support the findings of this study can be made available upon request to the corresponding author.

\section{References}

[1] Miglani S. Burden of dental caries in India: Current scenario and future strategies. Int J Clin Pediatr Dent 2020; 13(2):155-9. https://doi.org/10.5005/jp-journals-10005-1733

[2] Chen X, Daliri EB, Kim N, Kim JR, Yoo D, Oh DH. Microbial etiology and prevention of dental caries: Exploiting natural products to inhibit cariogenic biofilms. Pathogens 2020; 9(7):569. https://doi.org/10.3390/pathogens9070569

[3] Vila T, Sultan AS, Montelongo-Jauregui D, Jabra-Rizk MA. Oral Candidiasis: A disease of opportunity. J Fungi 2020; 6(1):15. https://doi.org/10.3390/jof6010015

[4] Nagarajappa R, Batra M, Sharda AJ, Asawa K, Sanadhya S, Daryani H, et al. Antimicrobial effect of Jasminum grandiflorum L. and Hibiscus rosa-sinensis L. extracts against pathogenic oral microorganisms - An in vitro comparative study. Oral Health Prev Dent 2015; 13(4):341-8. https://doi.org/10.3290/j.ohpd.a30601

[5] Ali EMM, Almagboul AZI, Khgali SME, Gergeir UM. Antimicrobial activity of Cannabis sativa L. Chin Med 2012; 3:61-4. https://doi.org/10.4236/cm.2012.31010

[6] Khan BA, Warner P, Wang H. Antibacterial property of hemp and other natural fiber plants - A review. BioRes 2014; 9(2):3642-59. https://doi.org/10.15376/biores.9.2.3642-3659

[7] Verma RS, Padalia RC, Verma SK, Chauhan A, Darokar MP. The essential oil of 'bhang' (Cannabis sativa L.) for nonnarcotic applications. Curr Sci 2014; 107(4):645-50.

[8] Cooper ZD, Haney M. Actions of delta-9-tetrahydrocannabinol in cannabis: relation to use, abuse, dependence. Int Rev Psychiatry 2009; 21(2):104-12. https://doi.org/10.1080/09540260902782752

[9] Beheshti-Rouy M, Azarsina M, Rezaie-Soufi L, Alikhani MY, Roshanaie G, Komaki S. The antibacterial effect of sage extract (Salvia officinalis) mouthwash against Streptococcus mutans in dental plaque: a randomized clinical trial. Iran J Microbiol 2015; 7(3):173-7.

[10] Ghorbani A, Esmaeilizadeh M. Pharmacological properties of Salvia officinalis and its components. J Tradit Complement Med 2017; 7(4):433-40. https://doi.org/10.1016/j.jtcme.2016.12.014 
[11] Hamidpour M, Hamidpour R, Hamidpour S, Shahlari M. Chemistry, pharmacology, and medicinal property of sage (Salvia) to prevent and cure illnesses such as obesity, diabetes, depression, dementia, lupus, autism, heart disease, and cancer. J Tradit Complement Med 2014; 4(2):82-8. https://doi.org/10.4103/2225-41 10.130373

[12] Beheshti-Rouy M, Azarsina M, Rezaie-Soufi L, Alikhani MY, Roshanaie G, Komaki S. The antibacterial effect of sage extract (Salvia officinalis) mouthwash against Streptococcus mutans in dental plaque: a randomized clinical trial. Iran J Microbiol 2015; 7(3):173-7.

[13] Stahl V, Vasudevan K. Comparison of efficacy of Cannabinoids versus commercial oral care products in reducing bacterial content from dental plaque: a preliminary observation. Cureus 2020; 12(1):e6809. https://doi.org/10.7759/cureus.6809

[14] Bauer AW, Kirby WMM, Sherries JC, Truck M. Antibiotic susceptibility testing by standardized single disc method. Am J Clin Pathol 1966; 45:493-6.

[15] McFarland J. The nephelometer: an instrument for estimating the number of bacteria in suspensions used for calculating the opsonic index and for vaccines. JAMA 1907; 49(14):1176-8. https://doi.org/10.1001/jama.1907.25320140022001f

[16] Lopresti AL. Salvia (Sage): A review of its potential cognitive-enhancing and protective effects. Drugs R D 2017; 17(1):53-64. https://doi.org/10.1007/s40268-016-0157-5

[17] Pierozan MK, Pauletti G, Rota L, Atti dos Santos AC, Lerin L, Di Luccio M, et al. Chemical characterization and antimicrobial activity of essential oils of salvia L species. Cienc Tecnol Aliment 2009; 29(4):764-70. https://doi.org/10.1590/So101-20612009000400010

[18] Sookto T, Srithavaj T, Thaweboon S, Thaweboon B, Shrestha B. In vitro effects of Salvia officinalis L. essential oil on Candida albicans. Asian Pac J Trop Biomed 2013; 3(5):376-80. https://doi.org/10.1016/S222 1-1691(13)60080-5 